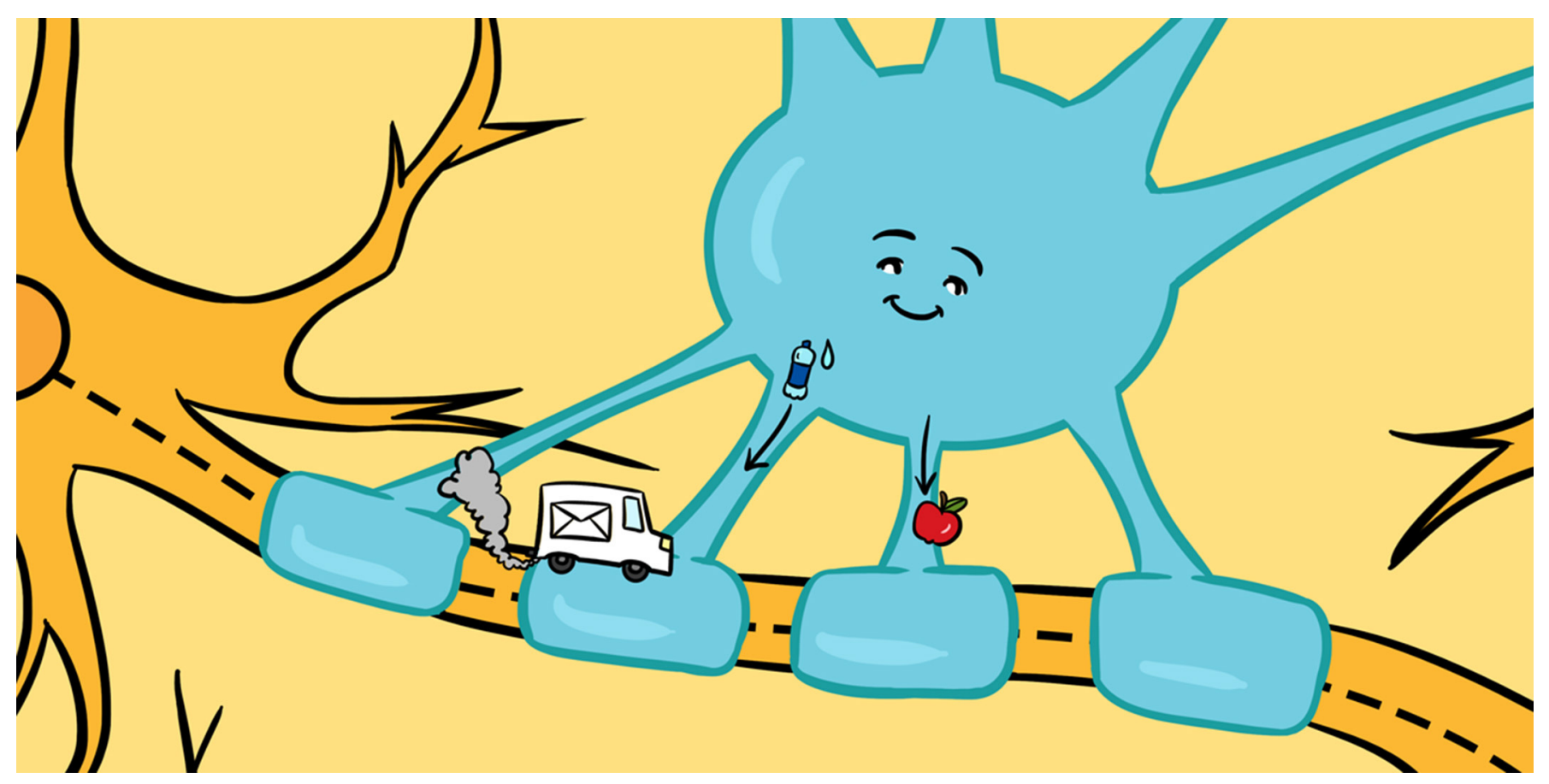

\title{
HOW OLIGODENDROCYTES HELP THE BRAIN FUNCTION
}

\section{Tracey A. C. S. Suter * and Zhigang He}

Boston Children's Hospital, Harvard Medical School, Boston, MA, United States

YOUNG REVIEWERS:

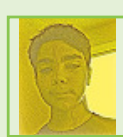

JOHN

HENRY

AGE: 11

Q.7. RYDER

AGE: 11

\section{NEURON}

A cell found in the brain and spinal cord that is specialized for communication across the body.
Imagine you had a really important message that you had to deliver to your friend as quickly as possible. Would you send your friend a handwritten letter through the postal service that would arrive in a few days? Or would you send an email, which gets delivered almost instantly? A neuron's job is to speedily send messages across the brain, spinal cord, and body. Neurons receive help with performing this important job from another kind of cell, called oligodendrocytes. In this article, we describe how oligodendrocytes help neurons rapidly send their messages, and how scientists are trying to protect and replace oligodendrocytes that are damaged in diseases like multiple sclerosis, or after a brain injury.

\section{SENDING MESSAGES THROUGHOUT THE BODY}

Neurons are like the mail carriers of the body; they are responsible for transmitting messages throughout the brain and the body. To send these communications, a neuron has a special shape: a long, 
Figure 1

(A) In babies, neurons do not have any myelin covering them. (B) Gradually, as a child grows up, oligodendrocytes wrap axons in myelin. (C) One oligodendrocyte can myelinate many axons at once. If you were to slice through a myelinated neuron, you would see the myelin wrapped around the axon in layers. On the right, you can see a real picture of myelin wrapped around axons.

\section{AXON}

A long, tube-like extension that allows a neuron to

communicate with far-away parts of the brain and body.

\section{OLIGODENDROCYTE}

A cell with branches that wrap myelin around axons.

\section{MYELIN}

A fatty membrane wrapped around neurons, which is made by oligodendrocytes.

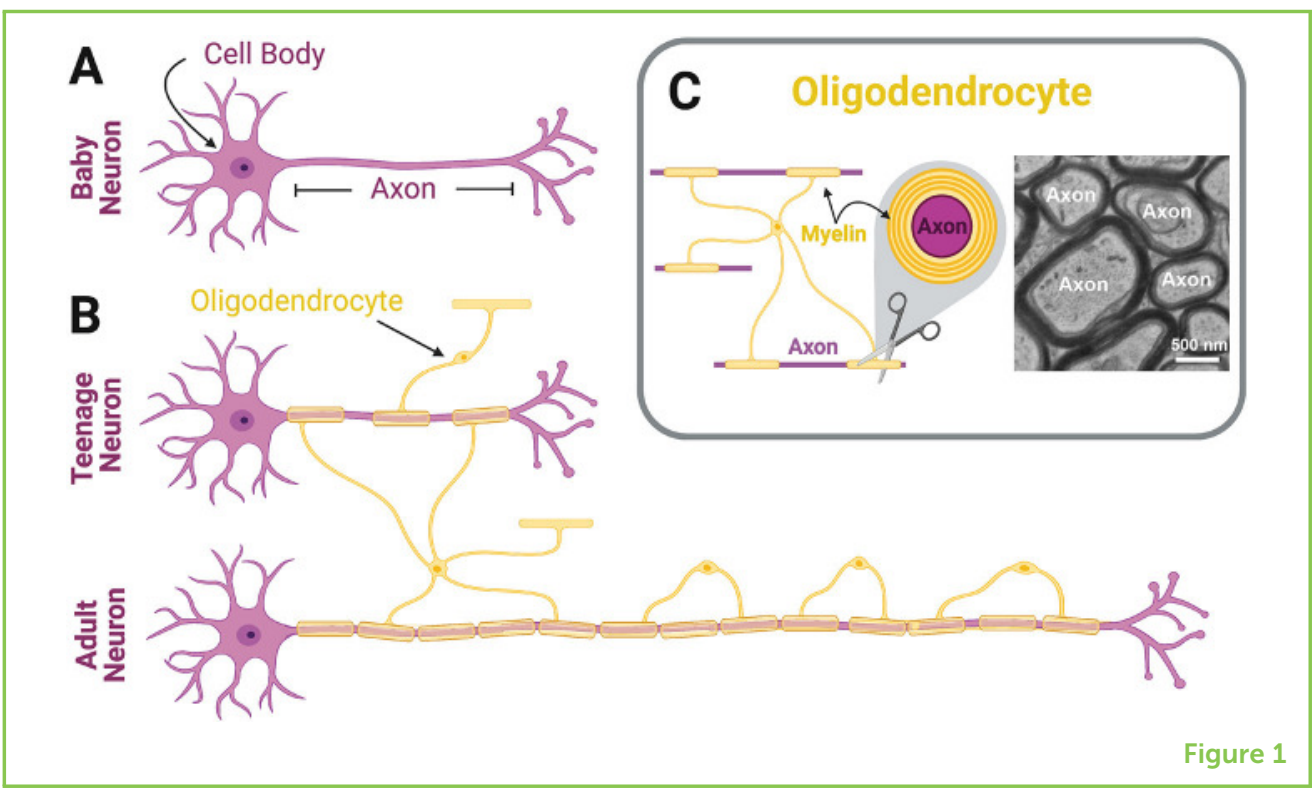

tube-like extension, called an axon, which extends out toward its target (Figure 1A). You can think of axons like the roads the mail carrier has to drive along to deliver letters. But not all roads or delivery routes are the same. Some roads might be longer than others, and some roads might have potholes or traffic, all of which can slow the delivery of mail. This can be a problem if you have a really important message that needs to be received almost instantly.

To help speed up message delivery, neurons partner with special cells called oligodendrocytes. When neurons have help from oligodendrocytes, they can send communications at lightning speed, even if their axons are very long. The word oligodendrocyte may sound a bit strange, but the name describes the cells' special role. Like many words in biology, it comes from Greek and means "cell with few branches." One oligodendrocyte can have up to 50 different branches [1]. Each branch reaches out to grab onto an axon (Figure 1B). The oligodendrocyte then wraps its branch around the axon over and over again, like rolling up a carpet (Figure 1C) [2]. The stuff wrapped around the axon is called myelin, and the act of an oligodendrocyte wrapping its myelin around an axon is called myelination.

When a baby is first born, the baby's neurons do not have any help from oligodendrocytes (Figure 1A) [2,3]. The baby's brain is working, but its messages are being delivered a little slowly, and some might get "lost in the mail." As we get older, oligodendrocytes start to extend their branches to wrap around the axons in the brain. As this happens, neurons get faster and faster at sending messages. Eventually, when we are about $25-30$ years old, all the axons that need help from oligodendrocytes will be wrapped up in myelin (Figure 1B) [4]. Once neurons and oligodendrocytes are teamed up, neurons can communicate extremely quickly, like clicking "send" on an email. 
Figure 2

(A) A normal, healthy myelinated neuron in an adult brain. (B) When a myelinated neuron degenerates, both the axon and the myelin fall apart and die. (C) If oligodendrocytes are sick or dying, myelin falls off the axon in a process called demyelination. This can happen in multiple sclerosis. (D) If the axon is cut or the neuron is otherwise injured, both the axon and myelin fall apart and die. (E) Neurons can regrow, or regenerate, but regenerated neurons lack myelin on their axons.

\section{DEGENERATION}

The death of axons due to injury or disease.

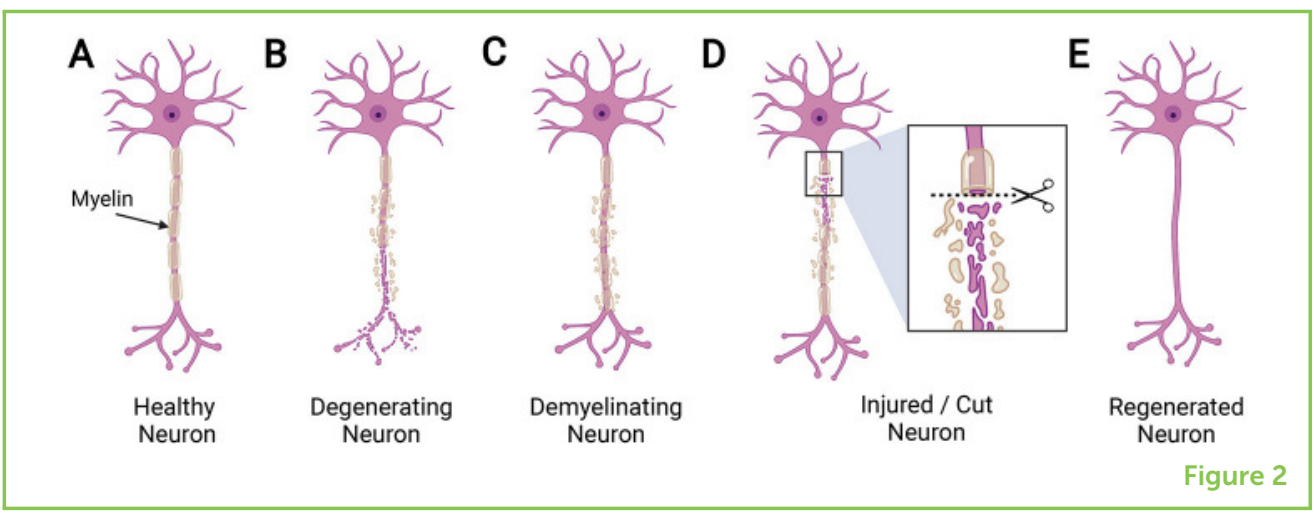

What exactly is myelin, and how does it help the neurons send faster messages? Myelin is composed of a fatty substance that gives it the ability to insulate neurons, like the plastic coating around the metal wire of a power cord. The insulation provided by myelin keeps the message inside the neuron as the message travels along the axon. If an axon does not have myelin, the message will gradually leak out or weaken as it travels down the axon. If too much of the message is missing when it reaches the end of the axon, the message might be undeliverable or incomplete! So, in addition to speeding up the delivery of messages, myelin is essential for keeping messages readable and accurate upon delivery.

Delivering messages all day takes a lot of work. Our mail carriers need to drink water and have some snacks during the day to make sure they have enough energy to make all their deliveries. Neurons also require a lot of nutritional support because they are constantly working too. Since oligodendrocytes are in such close contact with neurons, they are the perfect cells to help make sure neurons have all the food and water they need. So, in addition to helping with message delivery, oligodendrocytes provide neurons with the nutritional support they need to keep sending messages [3].

\section{NEURON INJURY AND REPAIR}

There are many things that can prevent oligodendrocytes from helping neurons (Figure 2). As you have already learned, a healthy adult neuron will have myelin wrapped around its axon. In diseases such as Alzheimer's disease, neurons get very sick and begin to die, in a process called degeneration. When a neuron degenerates, the myelin starts to fall off the axon-the axon becomes demyelinated. Multiple sclerosis is an example of a demyelinating disease in which axons lose their myelination. If the loss of oligodendrocytes is severe, neurons will also start to degenerate $[2,5]$. If an axon gets injured or cut, it can also become demyelinated and die [1]. Scientists believe that neurons and oligodendrocytes are so dependent on one another that if one cell starts dying, the other often does, too [6]. 
Figure 3

Baby oligodendrocytes, called oligodendrocyte precursor cells (OPCs), become mature, myelinating oligodendrocytes When OPCs get a signal from "helpful" microglia, the OPCs first increase in number. These new cells become immature oligodendrocytes, which have branches but do not yet myelinate axons. Eventually, immature oligodendrocytes become adult, myelinating oligodendrocytes that can wrap myelin around many different axons. However, "hurtful," or stressed-out microglia can send signals that keep the oligodendrocytes trapped in the immature phase.

\section{REGENERATION}

The regrowth of a cell or part of a cell, like the axon of a neuron.

\section{OLIGODENDROCYTE} PRECURSOR CELL

\section{A baby}

oligodendrocyte that can grow up to be an adult oligodendrocyte.

\section{MICROGLIA}

A cell that acts like the garbage man of the brain to remove debris produced by malfunctioning or dead cells.

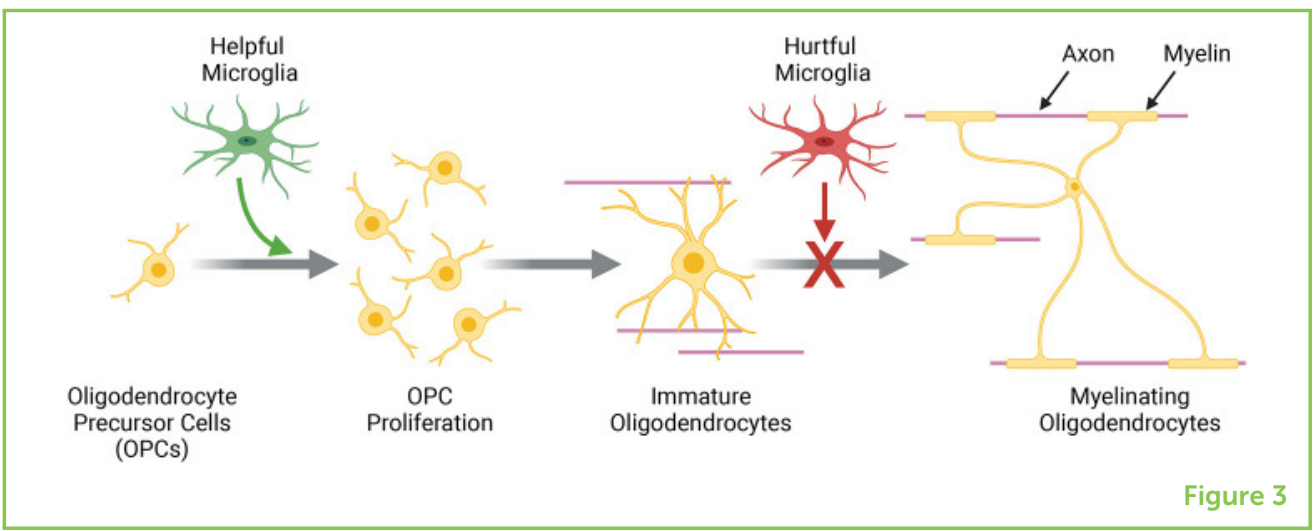

When a neuron regrows or repairs its axon, we call that regeneration. Because neurons are so essential for the brain's communication, scientists have been working to regenerate axons after injury or disease. But even when scientist get neurons to regenerate, those neurons are not myelinated by oligodendrocytes, which prevents the newly repaired neurons from performing their communication duties. In some cases, regenerated neurons will die without the support of the oligodendrocytes [3].

Scientists are trying to protect and regrow oligodendrocytes so that regenerated neurons can be remyelinated and brain functions can be restored. One amazing thing about oligodendrocytes is that they can replace themselves throughout a person's lifetime. Given all the work that oligodendrocytes do, it is easy to imagine that they might need to be replaced from time to time. Fortunately, the brain contains baby oligodendrocytes, which are called oligodendrocyte precursor cells (OPCs). So, when an old oligodendrocyte needs to be replaced, an OPC will first divide to make more OPCs. The newly made OPCs will start to develop into immature oligodendrocytes. At this stage they have branches, but they are not wrapping axons with myelin yet. Over time, immature oligodendrocytes will continue to develop, until they become mature myelinating oligodendrocytes (Figure 3) [7].

\section{WHAT STOPS NEW OLIGODENDROCYTES FROM HELPING NEURONS?}

Although we know that the development of OPCs into myelinating oligodendrocytes is possible and happens naturally, we do not know how to initiate this process after injury or disease. In the case of injury or disease, there are usually problems with other cells in the brain, too-not just neurons and oligodendrocytes. Recent work by scientists has shown that brain cells called microglia, which function like the garbage collectors within the brain, are key to generating new oligodendrocytes. Microglia travel around the brain and spinal cord, looking for "trash" to dispose of-like malfunctioning or dead cells. Microglia also send signals to other cells, including oligodendrocytes, 
telling them that something is wrong in the brain, or telling them that the coast is clear and it is safe to resume normal activities. When microglia come across a big injury or damaged area in the brain, they can become hyperactive and stressed out by all the things that are going wrong.

New research is showing that, after injury or disease, there are both "helpful" and "hurtful" microglia, both of which can affect oligodendrocytes (Figure 3) [8,9]. Initially, helpful microglia tell the OPCs that there are regenerated neurons that need to be myelinated. This signal from the helpful microglia results in an increased number of OPCs [6]. However, over time, these helpful microglia can become hurtful microglia. You can imagine that, if you are constantly surrounded by things that are going wrong or are broken, you might get a little stressed out. During the time it takes the OPCs to become immature oligodendrocytes, microglia become so overwhelmed that they start telling the immature oligodendrocytes to stop maturing and not to become myelinating oligodendrocytes [8].

To prevent microglia from stopping oligodendrocyte maturation, scientists have developed a drug that temporarily removes nearly all of the microglia from the brain [9]. This drug tells the hurtful microglia to self-destruct, and eliminates most, but not all, of the microglia in the brain. The big drop in the number of hurtful microglia is enough to allow immature oligodendrocytes to finish developing and wrap their myelin around regenerated axons [8]. Once the regenerated axons are myelinated by the newly matured oligodendrocytes, the drug is no longer needed and can be stopped. When the drug is removed, microglia will begin to replace themselves [9]. The one problem with this drug is that we do not want people to be without microglia, even for a short time. Microglia are essential for keeping the brain clear of debris and damaged cells, so if a person gets another head injury while taking the drug, there will be no helpful microglia to clean up. So, scientists are now working to make new drugs that stop hurtful microglia from preventing the generation of myelinating oligodendrocytes, while still allowing microglia to perform their other, helpful duties.

\section{CONCLUSIONS}

Neurons and oligodendrocytes work together to make sure messages are delivered as quickly as possible across the brain and body. When the brain gets injured or sick both neurons and oligodendrocytes can die-causing major communication failures. In the millions of patients with spinal cord injuries or with multiple sclerosis, these communication failures can result in people losing the ability to walk, or talk, or live a normal life. For this reason, scientists are working hard to regenerate neurons and oligodendrocytes after these injuries or diseases. The discovery of new treatments that help oligodendrocytes 
to remyelinate and support neurons could help improve the quality of life for many of these patients.

\section{ACKNOWLEDGMENTS}

Figures made with BioRender software (http://biorender.com). Thank you to the young reviewers and Susan Debad for making this article more accessible to a young audience! TS is supported by a T32 fellowship from NEI (T32EY007145) and a F32 fellowship from NEI (F32EY032779).

\section{REFERENCES}

1. Baumann, N., and Pham-Dinh, D. 2001. Biology of oligodendrocyte and myelin in the mammalian central nervous system. Physiol Rev. 81:871-927. doi: 10.1152/physrev.2001.81.2.871

2. Kuhn, S., Gritti, L., Crooks, D., and Dombrowski, Y. 2019. Oligodendrocytes in development, myelin generation and beyond. Cells. 8:1-23. doi: 10.3390/cells 8111424

3. Stadelmann, C., Timmler, S., Barrantes-freer, A., and Simons, M. 2019. Myelin in the central nervous system: structure, function, and pathology. Physiol Rev. 99:1381-431. doi: 10.1152/physrev.00031.2018

4. Fields, R. D. 2008. White matter matters. Brain Sci. 298:54-61. doi: 10.1038/ scientificamerican0308-54

5. Skaper, S. D. 2019. Oligodendrocyte Precursor Cells as a Therapeutic Target for Demyelinating Diseases. 1st ed. Cambridge, MA: Elsevier B.V. doi: 10.1016/bs. pbr.2019.03.013

6. Franklin, R. J. M., and Ffrench-Constant, C. 2008. Remyelination in the CNS: from biology to therapy. Nat Rev Neurosci. 9:839-55. doi: 10.1038/nrn2480

7. Pease-Raissi, S. E., and Chan, J. R. 2021. Building a (w)rapport between neurons and oligodendroglia : reciprocal interactions underlying adaptive myelination. Neuron 109:1258-1273. doi: 10.1016/j.neuron.2021.02.003

8. Wang, J., He, X., Meng, H., Li, Y., Dmitriev, P., Tian, F., et al. 2020. Robust myelination of regenerated axons induced by combined manipulations of GPR17 and microglia. Neuron. 108:876-86.e4. doi: 10.1016/j.neuron.2020.09.016

9. Li, Q., and Barres, B. A. 2018. Microglia and macrophages in brain homeostasis and disease. Nat Rev Immunol. 18:225-42. doi: 10.1038/nri.2017.125

SUBMITTED: 17 March 2021; ACCEPTED: 23 August 2021;

PUBLISHED ONLINE: 17 September 2021.

EDITED BY: Sara Busatto, Boston Children's Hospital and Harvard Medical School, United States

CITATION: Suter TACS and He Z (2021) How Oligodendrocytes Help The Brain Function. Front. Young Minds 9:682189. doi: 10.3389/frym.2021.682189 

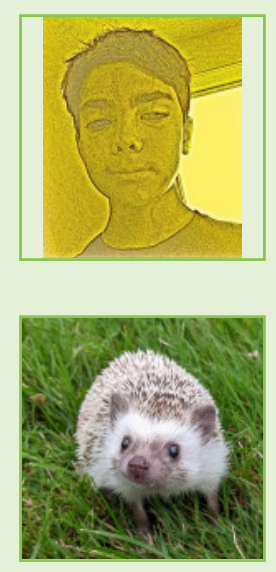

CONFLICT OF INTEREST: The authors declare that the research was conducted in the absence of any commercial or financial relationships that could be construed as a potential conflict of interest.

COPYRIGHT @ 2021 Suter and He. This is an open-access article distributed under the terms of the Creative Commons Attribution License (CC BY). The use, distribution or reproduction in other forums is permitted, provided the original author(s) and the copyright owner(s) are credited and that the original publication in this journal is cited, in accordance with accepted academic practice. No use, distribution or reproduction is permitted which does not comply with these terms.

\section{YOUNG REVIEWERS}

\section{JOHN HENRY, AGE: 11}

Hello, and thank you very much for reading this. I enjoy reading, playing Minecraft, and coding. I live in the USA at a location that cannot be shared for privacy reasons. I like to play soccer, swim, and hang out with my friends. Bye, and again, thank you for opening this pop up.

\section{RYDER, AGE: 11}

Ryder is a middle school student that likes baseball and math.

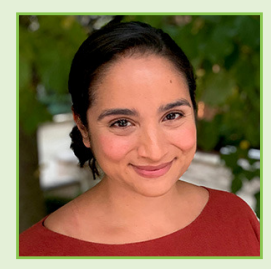

\section{AUTHORS}

\section{TRACEY A. C. S. SUTER}

Dr. Tracey Suter is a Neuroscientist at Harvard Medical School and Boston Children's Hospital. She received her Ph.D. from Brown University in 2019. Tracey has always been interested in how the brain functions. As she has gotten older, she has decided that she wants to help discover new ways to treat injuries and diseases of the brain and spinal cord. When she is not in the laboratory, Tracey enjoys hiking, traveling, and generally spending time outside. *tracey.suter@childrens.harvard.edu

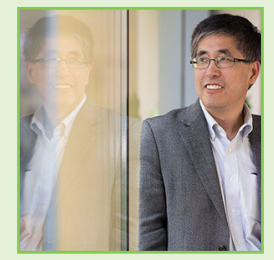

\section{ZHIGANG HE}

Dr. Zhigang He received his M.D. from Nanjing Medical College in China and his Ph.D. from the University of Toronto in Canada. He has led a research laboratory at Harvard Medical School and Boston Children's Hospital since 1999. His laboratory is focused on restoring function to the brain and spinal cord after injury or disease. He likes to come up with exciting new experiments and to mentor young scientists. 